\title{
Bronchiolitis obliterans syndrome occurs earlier in the post-lung allocation score era
}

\author{
Abbas Emaminia, MD, Sara A. Hennessy, MD, Tjasa Hranjec, MD, MS, Damien J. LaPar, MD, \\ Benjamin D. Kozower, MD, MPH, David R. Jones, MD, Irving L. Kron, MD, and Christine L. Lau, MD
}

Objectives: In 2005, the time-based waiting list for lung transplantation was replaced by an illness/benefit lung allocation score (LAS). Although short-term outcomes after transplantation have been reported to be similar before and after the new system, little is known about long-term results. The objective of this study was to evaluate the impact of LAS on the development of bronchiolitis obliterans syndrome as well as on overall 3-year and bronchiolitis obliterans syndrome-related survival.

\begin{abstract}
Methods: Data obtained from the United Network for Organ Sharing were used to review 8091 patients who underwent lung transplantation from 2002 to 2008. Patients were stratified according to time of transplantation into those treated before initiation of the LAS (pre-LAS group, January 2002-April 2005, $\mathrm{n}=3729$ ) and those treated after implementation of the score (post-LAS group, May 2005-May 2008, $\mathrm{n}=4362$ ). Overall, 3-year survivals for patient groups were compared using a univariate analysis, Cox proportional hazards model to generate a relative risk, and Kaplan-Meier curve analyses.
\end{abstract}

Results: During the 3-year follow-up period, bronchiolitis obliterans syndrome developed in $22 \%$ of lung transplant recipients $(\mathrm{n}=1801)$. Although the incidence of postoperative bronchiolitis obliterans syndrome development was similar between groups, post-LAS patients incurred fewer bronchiolitis obliterans syndrome-free days (609 \pm 7.5 vs $682 \pm 9 ; P<.0001 ; \log$-rank test $P=.0108)$ than did pre-LAS patients. Overall 3-year survival was lower in post-LAS patients and approached statistical significance $(P=.05)$. Similarly, bronchiolitis obliterans syndrome-related survival was worse for patients in the post-LAS group $(\log$-rank test $P=.01)$.

Conclusions: In the current LAS era, lung transplant recipients have significantly fewer bronchiolitis obliterans syndrome-free days after 3-year follow-up. Compared with the pre-LAS population, overall and bronchiolitis obliterans syndrome-related survival appears worse in the post-LAS era. Limitation of known risk factors for development of bronchiolitis obliterans syndrome-may prove even more important in this patient population. (J Thorac Cardiovasc Surg 2011;141:1278-82)

Although lung transplantation is a potentially life-saving procedure and the treatment of choice for the majority of end-stage lung diseases, long-term success rates are often limited by chronic allograft rejection. ${ }^{1,2}$ Mortality after lung transplantation remains the highest among all solid organ recipients, with 5- and 10-year survivals of 53\% and $27 \%$, respectively. ${ }^{3}$ Bronchiolitis obliterans syndrome (BOS) is a clinical condition characterized by irreversible airways obstruction, which accounts for approximately $30 \%$ of late mortality in lung transplant patients. ${ }^{4}$

Allocation of donor lungs for transplantation before 2005 was based on accumulated wait-list time without consideration of medical urgency or survival expectation. ${ }^{5}$ In the spring of 2005, the United Network for Organ Sharing

From the Department of Surgery, University of Virginia, Charlottesville, Va. Disclosures: Authors have nothing to disclose with regard to commercial support. Received for publication Aug 20,2010; revisions received Nov 4, 2010; accepted for publication Dec 16, 2010; available ahead of print Feb 14, 2011.

Address for reprints: Christine L. Lau, MD, University of Virginia Health System, Division of Thoracic and, Cardiovascular Surgery, PO Box 800679, Charlottesville, VA 22908-0679 (E-mail: cll2y@virginia.edu).

$0022-5223 / \$ 36.00$

Copyright (C) 2011 by The American Association for Thoracic Surgery doi:10.1016/j.jtcvs.2010.12.025
(UNOS) replaced the former system with a new lung allocation score (LAS) that considered wait-list urgency and posttransplant survival in the prioritization of organ allocation. The new system considers the 1-year survival of patients without lung transplantation as well as the predicted 1-year survival after transplantation. ${ }^{5-7}$ Concerns have arisen regarding its impact on short- and long-term outcomes of transplant recipients inasmuch as the new system prioritizes sicker patients to receive organs earlier. Accumulated evidence has revealed comparable short-term outcomes within the first year after transplantation. ${ }^{8,9}$

The objective of the current study was to evaluate the impact of LAS on the development of chronic lung rejection and BOS development. We hypothesized that BOS was more likely to develop in patients in the post-LAS era and that an increased incidence of BOS would result in higher mortality in the post-LAS group.

\section{PATIENTS AND METHODS \\ Data Source}

This study was reviewed by the University of Virginia Internal Review Board and granted exemption from approval and consent. Data for all patients undergoing lung transplantation was obtained from the UNOS 


\section{Abbreviations and Acronyms \\ BOS = bronchiolitis obliterans syndrome \\ COPD $=$ chronic obstructive pulmonary disease \\ ISHLT $=$ International Society of Heart and Lung \\ Transplantation \\ LAS = lung allocation score \\ PGD = primary graft dysfunction \\ UNOS $=$ United Network for Organ Sharing}

Standard Transplant Analysis and Research data set. The UNOS data set is a prospectively collected database of every organ donation and transplantation in the United States since 1987. Each transplant center collects and reports data to UNOS based on data collection forms provided by UNOS. All patient- and hospital-related identifiers are removed from published data sets to provide de-identified data for analysis.

\section{Study Design/Patient Characteristics}

A total of 8091 patients were identified in the UNOS database as having received lung transplants after January 2002. Patients admitted before the date and/or undergoing simultaneous heart and lung transplantation were excluded from the study. Lung transplant recipients were stratified into 2 groups on the basis of operative era: pre-LAS patients (transplantation between January 2002 and May 2005) and post-LAS patients (transplantation between May 2005 and May 2008). BOS was defined as a declining forced expiratory volume in 1 second in the absence of another cause according to International Society of Heart and Lung Transplantation (ISHLT) criteria. ${ }^{10}$ The incidence of postoperative BOS was defined as the development of BOS (regardless of stage) within 3 years after transplantation.

\section{Variables Examined and Outcomes Measured}

For all lung transplant recipients, patient demographics (eg, age, gender, race), pulmonary risk factors (eg, diagnosis, oxygen requirements), comorbid disease, operative features (eg, transplant type, LAS score, ischemic time), and postoperative outcomes (eg, dialysis, airway dehiscence, pulmonary infection, acute rejection) were analyzed. Similarly, relevant donor factors (eg, cytomegalovirus infection status, ABO status, infection status, creatinine, cause of death) were considered. The primary end point of the study was the time to BOS development for both pre- and post-LAS groups up to 3 years after lung transplantation. Secondary end points were overall 3 -year and BOS-related survival.

\section{Statistical Analysis}

Descriptive analysis comparing demographic data between the pre- and post-LAS groups was performed using univariate analysis. Continuous variables that were normally distributed were presented as a mean \pm standard error and compared using a 2-sample $t$ test for independent samples. Continuous variables that were not normally distributed were presented as a median and interquartile range with $P$ value generated through a group comparison using the Wilcoxon rank sum test. Categorical variables were analyzed using a $\chi^{2}$ or Fisher exact test. A comparison of time to BOS development as well as survival time was performed by the Kaplan-Meier method and the log-rank test. The differences were quantified using the Cox proportional hazards model via calculation of the hazard ratio. Hazard ratios were reported as unadjusted and adjusted for age and diagnosis as per previous publications. ${ }^{11}$ All analyses were performed using the SAS statistical software program (version 9.1.3 for Windows; SAS Institute, Inc, Cary, NC).

\section{RESULTS}

A total of 3729 lung transplant recipients were identified during the pre-LAS era, and 4362 recipients were identified in the post-LAS era. BOS developed in 1801 (22\%) of these patients within 3 years, whereas BOS either did not develop or else developed after 3 years in 6290 patients.

Perioperative characteristics for all lung transplant recipients are presented in Table 1 . There were differences in gender, creatinine, history of malignancy, ischemic time, and transplant type. As expected, there were significant differences between the pre- and post-LAS groups on recipient diagnosis as well. Whereas the pre-LAS group had a greater number of patients with chronic obstructive pulmonary disease (COPD), the post-LAS group had a greater number of patients with pulmonary fibrosis. There were also significant differences observed in the type of transplants being performed, single versus double, likely owing to a change in transplantation protocols over those 2 time periods. The 2 groups were, however, similar with respect to age as well as to the presence of preoperative cerebrovascular disease and peripheral vascular disease.

Lung transplant recipients in the post-LAS group incurred significantly more postoperative complications (Table 2). In the post-LAS group, there was a higher incidence of infection $(40.9 \%$ vs $46.8 \% ; P<.0001$ ), as well as a greater incidence of new-onset dialysis $(5.2 \%$ vs $5.9 \% ; P<.0001)$ after transplantation. Hospital length of

TABLE 1. Patients' perioperative characteristics

\begin{tabular}{|c|c|c|c|}
\hline & $\begin{array}{c}\text { Pre-LAS } \\
(\mathbf{n}=\mathbf{3 7 2 9})(\%)\end{array}$ & $\begin{array}{c}\text { Post-LAS } \\
(n=4362)(\%)\end{array}$ & $\begin{array}{c}P \\
\text { value* }\end{array}$ \\
\hline Age $($ mean $\pm \mathrm{SD})$ & $49.1 \pm 14.7$ & $51.3 \pm 14.9$ & .60 \\
\hline Gender (male) & $1906(51.1)$ & $2504(57.4)$ & $<.001$ \\
\hline Creatinine & 0.93 & 0.87 & .002 \\
\hline Cerebrovascular disease & $25(0.7)$ & $21(0.9)$ & .06 \\
\hline Peripheral vascular disease & $40(1.1)$ & $25(1.1)$ & .97 \\
\hline History of cigarette use & 335 (58.6) & $2386(60.9)$ & .28 \\
\hline History of malignancy & $121(3.2)$ & $250(5.7)$ & $<.0001$ \\
\hline Diagnosis & & & $<.0001$ \\
\hline COPD & $1384(37.1)$ & $1241(28.5)$ & \\
\hline Pulmonary fibrosis & $790(21.2)$ & $1293(29.6)$ & \\
\hline Cystic fibrosis & $598(16.0)$ & $621(14.2)$ & \\
\hline $\begin{array}{l}\text { Alpha- } 1 \text { antitrypsin } \\
\text { deficiency }\end{array}$ & $220(5.9)$ & $129(3.0)$ & \\
\hline $\begin{array}{l}\text { Pulmonary } \\
\text { hypertension }\end{array}$ & $137(3.7)$ & $87(2.0)$ & \\
\hline Bronchiectasis & $78(2.1)$ & $75(1.7)$ & \\
\hline $\begin{array}{l}\text { Days on waiting } \\
\quad \text { list (mean } \pm \mathrm{SD})\end{array}$ & $436.2 \pm 455.8$ & $263.4 \pm 448.7$ & $<.0001$ \\
\hline \multicolumn{4}{|l|}{ Transplant type } \\
\hline Single & $1682(45.2)$ & $1616(37.1)$ & $<.0001$ \\
\hline Double & $2043(54.8)$ & $2745(62.9)$ & \\
\hline $\begin{array}{l}\text { Ischemic time }(\mathrm{h}) \\
\quad(\text { mean } \pm \mathrm{SD})\end{array}$ & $4.7 \pm 1.7$ & $5.1 \pm 1.7$ & $<.0001$ \\
\hline
\end{tabular}

$S D$, Standard deviation; $C O P D$, chronic obstructive pulmonary disease. *Significance $P<.05$. 
TABLE 2. Patients' postoperative characteristics.

\begin{tabular}{lccc}
\hline & $\begin{array}{c}\text { Pre-LAS } \\
(\mathbf{n}=\mathbf{3 7 2 9})(\%)\end{array}$ & $\begin{array}{c}\text { Post-LAS } \\
(\mathbf{n}=\mathbf{4 3 6 2})(\%)\end{array}$ & $\begin{array}{c}\boldsymbol{P} \\
\text { value* }\end{array}$ \\
\hline BOS at 3 y & $799(21.4)$ & $1002(23.0)$ & .09 \\
$\begin{array}{l}\text { BOS-free days } \\
\quad(\text { mean } \pm \text { SE) }\end{array}$ & $682.6 \pm 9.0$ & $609.9 \pm 7.5$ & $<.0001$ \\
$\begin{array}{l}\text { Mortality at 3 y } \\
\quad(\text { mean } \pm \text { SE) }\end{array}$ & $402.2 \pm 9.6$ & $380.1 \pm 8.5$ & .08 \\
Postoperative dialysis & $193(5.2)$ & $256(5.9)$ & $<.0001$ \\
Postoperative stroke & $64(1.7)$ & $67(1.5)$ & $<.0001$ \\
Postoperative infection & $1526(40.9)$ & $1115(46.8)$ & $<.0001$ \\
Length of stay (d) & $23.6 \pm 0.5$ & $24.9 \pm 0.5$ & .06 \\
$\quad($ mean \pm SD) & & & \\
\hline SE, Standard error; SD, standard deviation; BOS, bronchiolitis obliterans syndrome.
\end{tabular}

* Significance $P<.05$.

stay after transplantation was similar between groups (preLAS $=23.6 \pm 0.5$ days vs post-LAS $=24.9 \pm 0.5$ days; $P=.06)$.

The incidence of BOS development at 3 years was similar between patients in both pre- and post-LAS groups $(21.4 \%$ vs $23.0 \% ; P=.09$ ). However, lung transplant recipients in the post-LAS group tended to have BOS develop earlier with significantly fewer BOS-free days compared with those in the pre-LAS group $(609.9 \pm 7.5$ vs $682.6 \pm 9.0$; unadjusted hazard ratio of $1.318 ; P<.0001)$. Importantly, the hazard ratio did not change after adjusting for age and diagnosis, and Kaplan-Meier analysis demonstrated significantly decreased BOS-free survival for patients in the post-LAS group compared with pre-LAS patients (Figure 1; log-rank $P<.0001$ ).

A trend toward lower overall 3-year survival was observed among post-LAS patients and approached statistical significance $(\log -$ rank $P=.05)$. Among the subset of lung transplant recipients in whom BOS developed, similar mortality rates were observed between the 2 groups $(P=.7)$. However, patients in the post-LAS era demonstrated de-

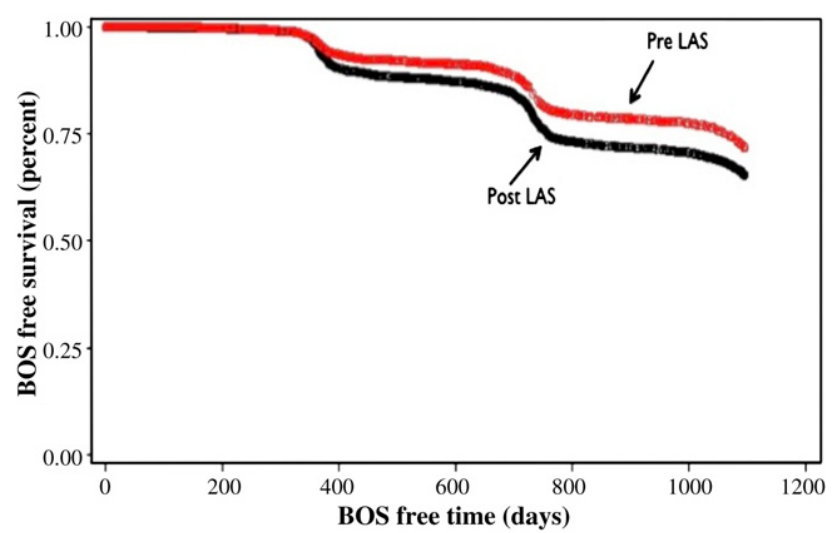

FIGURE 1. Kaplan-Meier curve of the development of the bronchiolitis obliterans syndrome $(B O S)$ demonstrates a significant decrease in BOSfree days for patients in the post-LAS group compared to those in the pre-LAS group $(\log -$ rank test $P<.0001)$. LAS, Lung allocation score. creased BOS-related survival compared with those in the pre-LAS era (unadjusted hazard ratio $=1.238 ; P=.01$; Figure 2).

\section{DISCUSSION}

In this study, the impact of LAS on the development of BOS within 3 years after transplantation was evaluated. Our results indicate that the number of lung transplantations has increased in recent years after the implementation of this new allocation score. Since the development of the LAS, sicker patients with higher LASs have been reported to undergo lung transplantation compared with those in the preLAS era. ${ }^{9}$ Herein, we have also demonstrated that patients in the post-LAS era have fewer BOS-free days compared with those in the pre-LAS era. Despite these results, the rate of development of BOS was not significantly different. In addition, our analyses suggest a trend toward lower overall 3-year survival within post-LAS lung transplant patients. Importantly, with respect to BOS-related survival, this trend suggests that patients in the current, post-LAS era died significantly earlier than did those in the pre-LAS era.

BOS continues to be a principal complication after lung transplantation and the leading cause of death for those who survive beyond the first year after the surgery. ${ }^{12}$ The 2009 ISHLT registry report revealed that among more than 10,000 recipients who survived at least 14 days, BOS developed in $28 \%$ by 2.5 years after transplantation and in $74 \%$ by 10 years. ${ }^{13}$ In addition, the importance of timing of BOS development has revealed that earlier development of BOS after transplantation has been associated with a worse functional and vital prognosis as well as graft failure. ${ }^{14}$ In our analysis, the $22 \%$ incidence of BOS at 3 years' follow-up is in agreement with previously reported national trends. However, the important finding of equivalent BOS development rates among lung transplant recipients in the pre- and post-LAS eras highlight the recent success of

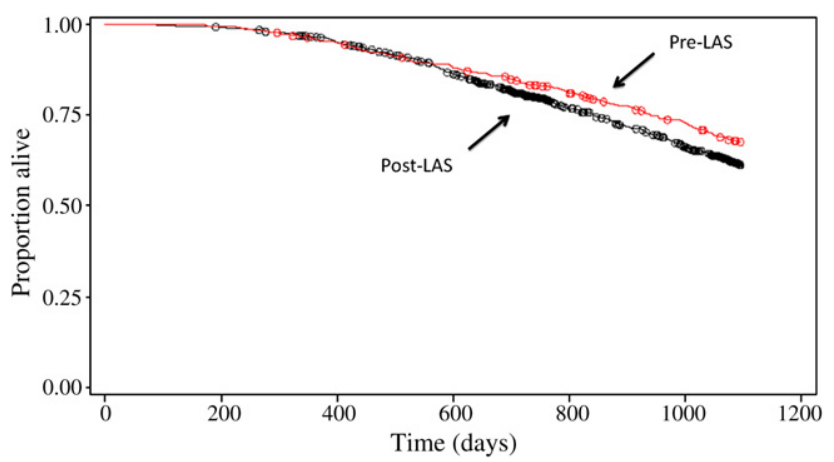

FIGURE 2. Kaplan-Meier curve for 3-year bronchiolitis obliterans syndrome-related survival among patients in both pre- and post-LAS groups. Among this cohort, survival was lower for patients in the post-LAS group compared with the pre-LAS group (log-rank test $P=.01)$. LAS, Lung allocation score. 
lung transplantation in a reportedly sicker patient population. The earlier development of BOS, as seen in the postLAS population in the current study, is equivalent to more rapid deterioration of transplant-related morbidities. Furthermore, BOS-related mortality is also accelerated, and the life expectancy of such population is significantly decreased.

Appropriate organ allocation for lung transplantation has become critical considering current donor shortages. Beginning in 1990, organ allocation for lung transplantation was based on waiting time. ${ }^{6}$ However, in May 2005, the Organ Procurement and Transplantation Network implemented the new LAS system to allocate lungs to candidates based on wait-list urgency and posttransplant survival. Wait-list urgency was defined as the expected number of days patients live during the next year without transplantation, and posttransplant survival was the expected number of days survived after transplantation. ${ }^{6}$ The main objectives of the LAS were to decrease wait-list mortality, improve recipient selection, and increase transplant benefits for recipients.

On the basis of available data, the LAS system appears to have achieved its short-term goals. Since implementation of the new system, there has been significant reduction in waitlist time, ${ }^{9}$ and the new allocation system has significantly decreased wait-list mortality. ${ }^{15}$ In fact, the annual death rate for wait-list patients has decreased from 135 per 1000 patient-years at risk in 2004 to 128 in $2008 .{ }^{16}$ Moreover, adoption of the LAS has improved recipient selection for lung transplantation. Accumulating data, including that of the present study, indicate that a shift in primary diagnostic indication from COPD to idiopathic pulmonary fibrosis has occurred since the introduction of the LAS system. ${ }^{7-9,17}$ The data presented here are consistent with a report by Chen and colleagues $^{8}$ on the decreased rate of transplantation for patients with primary pulmonary hypertension despite higher LAS. Although the reasons behind this are not entirely clear, fewer patients with primary pulmonary hypertension are listed and transplanted given the improvements in medical treatment.

Improved lung transplant benefits in the post-LAS era can be extrapolated from reported short- or long-term outcomes. In a previous study, we reported on outcomes of 341 lung transplant patients from 5 US centers and documented that despite significantly higher intensive care unit lengths of stay and prolonged ventilatory support in post-LAS patients, total hospital stay, hospital mortality, and 1-year survival were not adversely affected by the new allocation system. ${ }^{9}$ Other series have further investigated 1-year mortality rates of pre- and post-LAS recipients. McCue and associates ${ }^{18}$ reported a 1-year survival advantage among post-LAS patients compared with the pre-LAS patients. To the contrary, 2 larger studies failed to show 1-year survival advantages for post-LAS patients. ${ }^{9,17}$ In another study, Chen and associates ${ }^{8}$ failed to demonstrate any significant differences in 1-year mortality with respect to transplant indication (cystic fibrosis, COPD, idiopathic pulmonary arterial hypertension, and idiopathic pulmonary fibrosis). There remains controversy; however, 2 recent studies have demonstrated that patients with higher LAS had worse 30-day, 90-day, and 1-year survivals. ${ }^{1119}$

In this study, we have extended the examination of outcomes in the post-LAS era to investigate whether adoption of the LAS has achieved its objectives to maximize benefits to lung transplant recipients beyond the first year after transplantation. To our knowledge, the current study is the first to evaluate the impact of LAS on long-term outcomes. Considering that the reported median time to diagnosis of BOS is 16 to 20 months after transplantation, ${ }^{20}$ we chose to monitor all patients for 36 months to ensure sufficient time for the development of signs and symptoms of BOS. Consequently, the LAS system appears to have successfully allocated organs to higher risk patients with no significant change in the rate of chronic rejection. This finding disproves our first hypothesis of worse long-term outcomes in the post-LAS group. However, these patients are still at higher risk for earlier development of BOS, which is shown to result in earlier mortality and shorter life span after transplantation. In addition to fewer BOS-free days, patients in the post-LAS era had higher infection rates and significantly more renal failure. One explanation for decreased BOS-free days in post-LAS patients may be the increased rate of primary graft dysfunction (PGD). The correlation between PGD and BOS has been previously described in a cohort of 334 adult lung transplant recipients. ${ }^{21}$ In this series, Daud and colleagues ${ }^{21}$ revealed that recipients who had PGD have an increased risk of BOS that was independent of acute rejection, lymphocytic bronchitis, and respiratory viral infections. In a separate study, Huang and associates $^{22}$ demonstrated the impact of PGD grade within the first 3 days after transplantation on BOS development. They demonstrated that PGD development was a significant risk factor for BOS development and progression.

Both alloimmune-related (eg, acute cellular rejection, lymphocytic bronchitis, HLA mismatch) and nonalloimmunerelated risk factors (eg, PGD, gastroesophageal reflux disease) have been implicated as potential risk factors for the development of BOS. ${ }^{23} \mathrm{We}^{2}$ have recently reported donor factors (donor age, current history of smoking, pulmonary infection, donor hyperoxia) as important contributors to the development of BOS.

Prolonged ischemic time has been reported as a potential risk factor for the development of BOS. The results of a large cohort of 752 patients suggest a close relationship between graft ischemic time and long-term survival after single and double lung transplantation, but not development of BOS. ${ }^{24}$ In addition, Fiser and associates ${ }^{25}$ showed a trend toward increased BOS with ischemic time of more than 6 hours, but this did not reach statistical significance. 
Moreover, several other studies failed to demonstrate a significant increase in the onset, progression, and prognosis of BOS in patients with longer ischemic times. ${ }^{26-28}$

The overall infection rate was higher in the post-LAS patients, which could potentially contribute to the development of BOS. Botha and colleagues ${ }^{29}$ have recently shown a strong association between allograft colonization with Pseudomonas aeruginosa and the development of BOS within 2 years of transplant. They have demonstrated shorter BOS-free days in patients without any pretransplant bacterial reservoir developing de novo allograft pseudomonal colonization as compared with those remaining free of colonization.

There are several limitations of this study to note. The retrospective study design introduces inherent selection bias. In addition, the possibility for variations in reported data must be considered as individual centers capture and may interpret patient data differently. In addition, UNOS does not allow for the calculation of LAS for patients enrolled before 2005 . Thus, our ability to directly compare mean LAS in both eras is constrained. Consequently, our belief that patients in the pre-LAS group represent patient with lower scores is based on our institutional lung transplantation database and a recently reported multicenter investigation. ${ }^{9}$ UNOS also does not provide data on the incidence of PGD, and this may have an impact on the number of patients reported as having developed BOS to the UNOS. Furthermore, the UNOS database does not record stages of BOS, which limits our ability to extrapolate advancing BOS stage as a correlate to compromised long-term patient outcomes. Types of antirejection regimens are not included in the UNOS database and we were not able to consider this variable in the comparison between the 2 groups. Finally, the de-identified nature of the UNOS database also constrained any efforts to further scrutinize study groups to detect small clinical differences.

In conclusion, we have demonstrated that in the current LAS era, lung transplant recipients have significantly fewer BOS-free days after transplantation. Further, overall 3-year and BOS-related survival appears lower among lung transplant recipients since the adoption of the LAS system. Limitation of known risk factors for BOS development may help to improve posttransplant outcomes in this patient population.

\section{References}

1. Arcasoy SM, Kotloff RM. Lung transplantation. N Engl J Med. 1999;340: 1081-91.

2. Hennessy SA, Hranjec T, Swenson BR, Kozower BD, Jones DR, Ailawadi G, et al. Donor factors are associated with bronchiolitis obliterans syndrome after lung transplantation. Ann Thorac Surg. 2010;89:1555-62.

3. United States Department of Health and Human Services. 2007 optn/srtr annual report. www.ustransplant.org/annual_reports/current/113_surv-new_dh.Htm.

4. Verleden GM, Vos R, De Vleeschauwer SI, Willems-Widyastuti A, Verleden SE, Dupont LJ, et al. Obliterative bronchiolitis following lung transplantation: from old to new concepts? Transpl Int. 2009;22:771-9.

5. Egan TM, Kotloff RM. Pro/con debate: lung allocation should be based on medical urgency and transplant survival and not on waiting time. Chest. 2005;128:407-15.
6. Egan TM, Murray S, Bustami RT, Shearon TH, McCullough KP, Edwards LB, et al. Development of the new lung allocation system in the United States. Am J Transplant. 2006;6:1212-27.

7. Gries CJ, Mulligan MS, Edelman JD, Raghu G, Curtis JR, Goss CH. Lung allocation score for lung transplantation: impact on disease severity and survival. Chest. 2007;132:1954-61.

8. Chen H, Shiboski SC, Golden JA, Gould MK, Hays SR, Hoopes CW, et al. Impact of the lung allocation score on lung transplantation for pulmonary arterial hypertension. Am J Respir Crit Care Med. 2009;180:468-74.

9. Kozower BD, Meyers BF, Smith MA, De Oliveira NC, Cassivi SD, Guthrie TJ, et al. The impact of the lung allocation score on short-term transplantation outcomes: a multicenter study. J Thorac Cardiovasc Surg. 2008;135:166-71.

10. Estenne M, Maurer JR, Boehler A, Egan JJ, Frost A, Hertz M, et al. Bronchiolitis obliterans syndrome 2001: an update of the diagnostic criteria. J Heart Lung Transplant. 2002;21:297-310.

11. Liu V, Zamora MR, Dhillon GS, Weill D. Increasing lung allocation scores predict worsened survival among lung transplant recipients. Am J Transplant. 2010;10: 915-20.

12. Trulock EP, Edwards LB, Taylor DO, Boucek MM, Keck BM, Hertz MI. Registry of the International Society for Heart and Lung Transplantation: twenty-second official adult lung and heart-lung transplant report-2005. J Heart Lung Transplant. 2005;24:956-67.

13. Christie JD, Edwards LB, Aurora P, Dobbels F, Kirk R, Rahmel AO, et al. The registry of the International Society for Heart and Lung Transplantation: twenty-sixth official adult lung and heart-lung transplantation report-2009. J Heart Lung Transplant. 2009;28:1031-49.

14. Brugiere O, Pessione F, Thabut G, Mal H, Jebrak G, Leseche G, et al. Bronchiolitis obliterans syndrome after single-lung transplantation: impact of time to onset on functional pattern and survival. Chest. 2002;121:1883-9.

15. Hachem RR, Trulock EP. The new lung allocation system and its impact on waitlist characteristics and post-transplant outcomes. Semin Thorac Cardiovasc Surg. 2008;20:139-42.

16. Yusen RD, Shearon TH, Qian Y, Kotloff R, Barr ML, Sweet S, et al. Lung transplantation in the United States, 1999-2008. Am J Transplant. 2010;10:1047-68.

17. Merlo CA, Weiss ES, Orens JB, Borja MC, Diener-West M, Conte JV, et al. Impact of U.S. lung allocation score on survival after lung transplantation. J Heart Lung Transplant. 2009;28:769-75.

18. McCue JD, Mooney J, Quail J, Arrington A, Herrington C, Dahlberg PS. Ninetyday mortality and major complications are not affected by use of lung allocation score. J Heart Lung Transplant. 2008;27:192-6.

19. Russo MJ, Davies RR, Hong KN, Iribarne A, Kawut S, Bacchetta M, et al. Who is the high-risk recipient? predicting mortality after lung transplantation using pretransplant risk factors. J Thorac Cardiovasc Surg. 2009;138:1234-8.

20. Al-Githmi I, Batawil N, Shigemura N, Hsin M, Lee TW, He GW, et al. Bronchiolitis obliterans following lung transplantation. Eur J Cardiothorac Surg. 2006;30:846-51.

21. Daud SA, Yusen RD, Meyers BF, Chakinala MM, Walter MJ, Aloush AA, et al. Impact of immediate primary lung allograft dysfunction on bronchiolitis obliterans syndrome. Am J Respir Crit Care Med. 2007;175:507-13.

22. Huang HJ, Yusen RD, Meyers BF, Walter MJ, Mohanakumar T, Patterson GA, et al. Late primary graft dysfunction after lung transplantation and bronchiolitis obliterans syndrome. Am J Transplant. 2008;8:2454-62.

23. Belperio JA, Weigt SS, Fishbein MC, Lynch JP 3rd. Chronic lung allograft rejection: mechanisms and therapy. Proc Am Thorac Soc. 2009;6:108-21.

24. Thabut G, Mal H, Cerrina J, Dartevelle P, Dromer C, Velly JF, et al. Graft ischemic time and outcome of lung transplantation: a multicenter analysis. Am J Respir Crit Care Med. 2005;171:786-91.

25. Fiser SM, Kron IL, Long SM, Kaza AK, Kern JA, Cassada DC, et al. Influence of graft ischemic time on outcomes following lung transplantation. J Heart Lung Transplant. 2001;20:1291-6.

26. Gammie JS, Stukus DR, Pham SM, Hattler BG, McGrath MF, McCurry KR, et al. Effect of ischemic time on survival in clinical lung transplantation. Ann Thorac Surg. 1999;68:2015-9.

27. Snell GI, Rabinov M, Griffiths A, Williams T, Ugoni A, Salamonsson R, et al. Pulmonary allograft ischemic time: an important predictor of survival after lung transplantation. J Heart Lung Transplant. 1996;15:160-8.

28. Ueno T, Snell GI, Williams TJ, Kotsimbos TC, Smith JA, Rabinov M, et al. Impact of graft ischemic time on outcomes after bilateral sequential single-lung transplantation. Ann Thorac Surg. 1999;67:1577-82.

29. Botha P, Archer L, Anderson RL, Lordan J, Dark JH, Corris PA, et al. Pseudomonas aeruginosa colonization of the allograft after lung transplantation and the risk of bronchiolitis obliterans syndrome. Transplantation. 2008;85:771-4. 